\title{
Backstepping Control of Induction Motor Fed by Five-Level NPC Inverter
}

\author{
Ali BOUCHAIB ${ }^{1,2}$, Abdellah MANSOURI ${ }^{1}$, Rachid TALEB ${ }^{2}$ \\ ${ }^{1}$ Electrical Engineering Department, ENP d'Oran, BP 1523 El-M'naouer, Oran, Algeria \\ Laboratoire d'Automatique et d'Analyse des Systèmes \\ ${ }^{2}$ Electrical Engineering Department, Hassiba Benbouali University, Chlef, Algeria \\ Laboratoire Génie Electrique et Energies Renouvelables (LGEER)
}

\begin{abstract}
In this paper we will present a contribution to the backstepping control for induction motor (IM) based on the principle of Field Orientated Control (FOC). This law is established step by step while ensuring the stability of the machine in the closed loop, by a suitable choice of the function Lyapunov, In addition it is executed to assure the convergence the error's speed tracking at all initials conditions are possible. Both the speed and the rotor flux are supposed obtained by sensors. The control of the IM by five-level NPC inverter generally uses Pulse-width modulation techniques (PWM). Finally, we represent some of the simulation results by simulations in Matlab/Simulink environment.
\end{abstract}

Keywords-Backstepping control; Five-level NPC inverter; Field orientated control; Induction motor

\section{INTRODUCTION}

The control of electric actuators plays a key role in the field of motion control called Mechatronics. Because the simplicity of a control, the DC motor have been the traditional choice for the accurate control with the very high dynamic performance for a large range. The actuators are hard and costly to construct for rapid applications and high power; it is heavy, with an important inertia of the rotor and large dimensions.

Since a long time the AC motor was the choice for industrial applications for high-power and constant speed. These actuators have advantages that the DC motor for simple rotor it has to be no brushes construction contrary to their nonlinear dynamics they have been considered unsuitable for high dynamic performance and hard to check.

The new discoveries in electronics powers as well as the apparition of new technologies of microprocessors lows the result of the advance's implementing non-linear checking exploiting ESPACE, DSP and AC machines have been replaced the DC machines in a large application's varieties, there are even plans in the future to replace the traditional choice of hydraulic and pneumatic actuators by the asynchronous motor. About applications include robotics, aviation, and space engines. Because of these factors, AC motors became interesting references problems to try new non-linear control. The challenge of the increasing number of applications and controlling problems has more the incentive to deal the physical systems class. The importance of electric actuators in industry thousands of paper, and book number with investigations in this field have published through the last thirty years, much time is lost, and it will be a hard undertaking to start all these approaches' details but this is not the objective of the work. The lack of natural decoupling between the inductor and rotor makes the control of the induction motor more difficult, opposite to its structural simplicity, the study of the modeling will be done in the usual context of simplifying hypotheses [1, 2].

Amongst the various techniques of harmonic elimination used there is the technique of multilevel structures. The latter is able to generate numerous voltage levels at the output of the converter. However, the complexity of its structure constitutes an important disadvantage for the number of semiconductors increases with desired levels.[3-5].

The principle of backstepping technique is to establish in a constructive manner the control law of the nonlinear system, considering some state variables as Virtual control and its interim control laws making The application of this backstepping technique on the IM depends on choosing a Lyapunov function [6], ensuring the overall stability of the system. It presents the advantage of being robust to parametric variations of the machine and a good references pursuit. The association of backstepping technique with FOC control gives the induction machine control interesting qualities of robustness. [7, 8].

This work is organized as follows. First, we present the model of IM. After that, we talk about the three-phase fivelevel NPC inverter. Next give a backstepping application on this IM model, where we will choose both current $i_{s d}, i_{s q}$ as virtual control, we propose to eliminate the conventional PI controller in the FOC of the machine and replace them with control laws by backstepping. Finally, we give some simulation results.

\section{PROBLEM Formulation}

The asynchronous motor can be described by five nonlinear differential equations, with two electric coordinates (stator current) and two magnetic coordinates (rotor speed), the stator voltages are the two physical inputs of the system. In a rotating frame $d$ and $q$-axes, the IM is described by: 


$$
\left[\begin{array}{c}
\dot{\Omega} \\
\dot{\varphi}_{r d} \\
\dot{\varphi}_{r q} \\
\dot{i}_{s d} \\
\dot{i}_{s q}
\end{array}\right]=\left[\begin{array}{c}
m\left(\varphi_{r d} i_{s q}-\varphi_{r q} i_{s d}\right)-c \Omega-\frac{1}{j} T_{l} \\
-a \varphi_{r d}+\left(\omega_{s}-p \Omega\right) \varphi_{r q}+a M i_{s d} \\
-a \varphi_{r q}-\left(c \omega_{s}-p \Omega\right) \varphi_{r d}+a M i_{s q} \\
b a \varphi_{r d}+b p \Omega \varphi_{r q}-\dot{i}_{s d}+\omega_{s} i_{s q}+m_{1} v_{s d} \\
b a \varphi_{r q}-b p \Omega \varphi_{r d}-\dot{i}_{s q}-\omega_{s} i_{s d}+m_{1} v_{s q}
\end{array}\right]
$$

where $i_{s d}, i_{s q}, v_{s d}, v_{s q}, \varphi_{r d}, \varphi_{r a}, \Omega, T_{l}$ and $\omega_{s}$ respectively denote the fluxes rotor, the voltage inputs stator, the currents stator, the angular speed, the loading torque and the stator frequency. The $s$ and $r$ subscripts refer to both rotor and stator. The setting are:

$$
\left\{\begin{array}{l}
a=R_{r} / L_{r} \\
b=M / \sigma L_{s} L_{r} \\
c=f_{v} / J \\
\gamma=\left(L_{r} R_{s}+M^{2} R_{r}\right) / \sigma L_{s} L_{r}^{2} \\
\sigma=1-\left(M^{2} / L_{s} L_{r}\right) \\
m=p M / J L_{r} \\
m_{1}=1 / \sigma L_{s}
\end{array}\right.
$$

we denote by $R_{S}$ and $R_{r}$ the resistances, $L_{s}$ and $L_{r}$ the self inductances, $M$ the mutual inductance between the stator and rotor windings, $P$ the number of pole-pair, $J$ the inertia of the system (motor and load) and $f_{v}$ the viscous damping coefficient.

The assumptions are respectively presented:

1) The currents stator are capable for measurement also they show the measurable system's outputs;

2) The load torque is unchanged, obscure and it is famous with its troubledness;

3) The resistance stator known as an overflowing parameter changing with temperature;

4) The remained parameters are given by offline identification with limited ambiguity and they are also fixed.

\section{MultiLeVEL INVERTER MODELLING}

The three-phase five-level NPC inverter, is demonstrated by Figure 1, it has three arms of IGBT or MOSFET with antiparallel diode and three arms of two diodes. Whereas Table 1 shows the five-level output voltage according the states of the switches.

TABLE I. The Switches State For THE 5-LeVel of OutPut Voltage $(\mathrm{K}=1,2,3)$

\begin{tabular}{|l|l|l|l|l|l|l|}
\hline $\boldsymbol{B}_{\text {TDk1 }}$ & $\boldsymbol{B}_{\boldsymbol{T D k} \mathbf{2}}$ & $\boldsymbol{B}_{\text {TDk } \mathbf{3}}$ & $\boldsymbol{B}_{\boldsymbol{T D k} \mathbf{4}}$ & $\boldsymbol{B}_{\text {TDk5 }}$ & $\boldsymbol{B}_{\boldsymbol{T D k} \mathbf{6}}$ & $\boldsymbol{V}_{\boldsymbol{k} \boldsymbol{M}}$ \\
\hline 1 & 1 & 1 & 0 & 0 & 0 & $2 U C$ \\
\hline 1 & 1 & 0 & 0 & 0 & 1 & $U C$ \\
\hline 1 & 0 & 0 & 1 & 0 & 1 & 0 \\
\hline 0 & 0 & 1 & 1 & 1 & 0 & $-U C$ \\
\hline 0 & 0 & 0 & 1 & 1 & 1 & $-2 U C$ \\
\hline
\end{tabular}

PMW strategy is the most discussed method of the selected switching control methods (in the literature). This strategy is based on comparison between several triangular signals to a sinusoidal reference [9-12]. In the case of fivelevel converter the strategy consists of comparing four triangular carries having the same frequency and amplitude to the sinusoidal reference. Thus, the reference waveform is placed in the middle of the carrier bands [13-15].

\section{ROBUST BACKSTEPPING AND FIELD ORIENTED CONTROL}

In this section, it is proposed to eliminate conventional PI regulators in vector control of the IM and replace them by backstepping control laws.

The controller design is done in two steps. First step, the control problem is to choose $i_{\text {sdref }}$ and $i_{\text {sqref }}$ in such a way to force $\Omega$ and $\varphi_{r d}$ to track their desired reference signals $\Omega_{r e f}$ and $\varphi_{\text {ref }}$ the second step is devoted to the current loops design: find the controls $v_{s d}$ and $v_{s q}$ such that the currents $i_{s d}$ and $i_{s q}$ converge fast to desired references $i_{\text {sdref }}$ and $i_{\text {sqref }}$ respectively. This design is detailed below.

Step 1: Start with the first equation of (2), we define $e_{1}, e_{2}$ errors and representing respectively

$$
\left\{\begin{array}{c}
e_{1}=\Omega_{\text {ref }}-\Omega \\
e_{2}=\varphi_{\text {ref }}-\varphi_{d}
\end{array}\right.
$$

The derivative of (2) is computed as

$$
\left\{\begin{array}{c}
\dot{e}_{1}=\dot{\Omega}_{r e f}-m \varphi_{d} i_{s q}+c \Omega+\frac{T_{l}}{J} \\
\dot{e}_{2}=\dot{\varphi}_{r e f}-\dot{\varphi}_{d}=\dot{\varphi}_{r e f}+a \varphi_{d}-a M i_{s d}
\end{array}\right.
$$

The first Lyapunov $v_{1}$ candidates chosen as:

$$
v_{1}=\frac{1}{2}\left(e_{1}^{2}+e_{2}^{2}\right)
$$

So, the derivative of (4) is computed as:

$$
\left\{\begin{array}{c}
\dot{v}_{1}=e_{1}\left(\dot{\Omega}_{r e f}-m \varphi_{d} i_{s q}+c \Omega+\frac{T_{l}}{j}\right) \\
+e_{2}\left(\dot{\varphi}_{r e f}+\alpha \varphi_{d}-a M i_{s d}\right)
\end{array}\right.
$$

The tracking objectives can be satisfied by choosing:

$$
\left\{\begin{array}{c}
\left(i_{s q}\right)_{r e f}=\frac{1}{a M} \frac{1}{m}\left[k_{1} e_{1}+\dot{\Omega}_{r e f}+c \Omega+\frac{T_{l}}{j}\right] \\
\left(i_{s d}\right)_{r e f}=\frac{1}{a M}\left[k_{2} e_{2}+\varphi_{\text {ref }}+a \varphi_{d}\right]
\end{array}\right.
$$

where $k_{1}$ and $k_{2}$ positive design constants that determine the closed loop dynamics.

The derivative of the function Lyapunov becomes:

$\dot{v}_{1}=k_{1} e_{1}{ }^{2}-k_{2} e_{2}{ }^{2}<0$

so $i_{\text {sqref }}$ and $i_{\text {sdref }}$ are asymptotically stable.

Step 2: Define other errors signals about currents:

$\left\{\begin{array}{l}e_{3}=i_{\text {sqref }}-i_{s q} \\ e_{4}=i_{\text {sdref }}-i_{s d}\end{array}\right.$ 


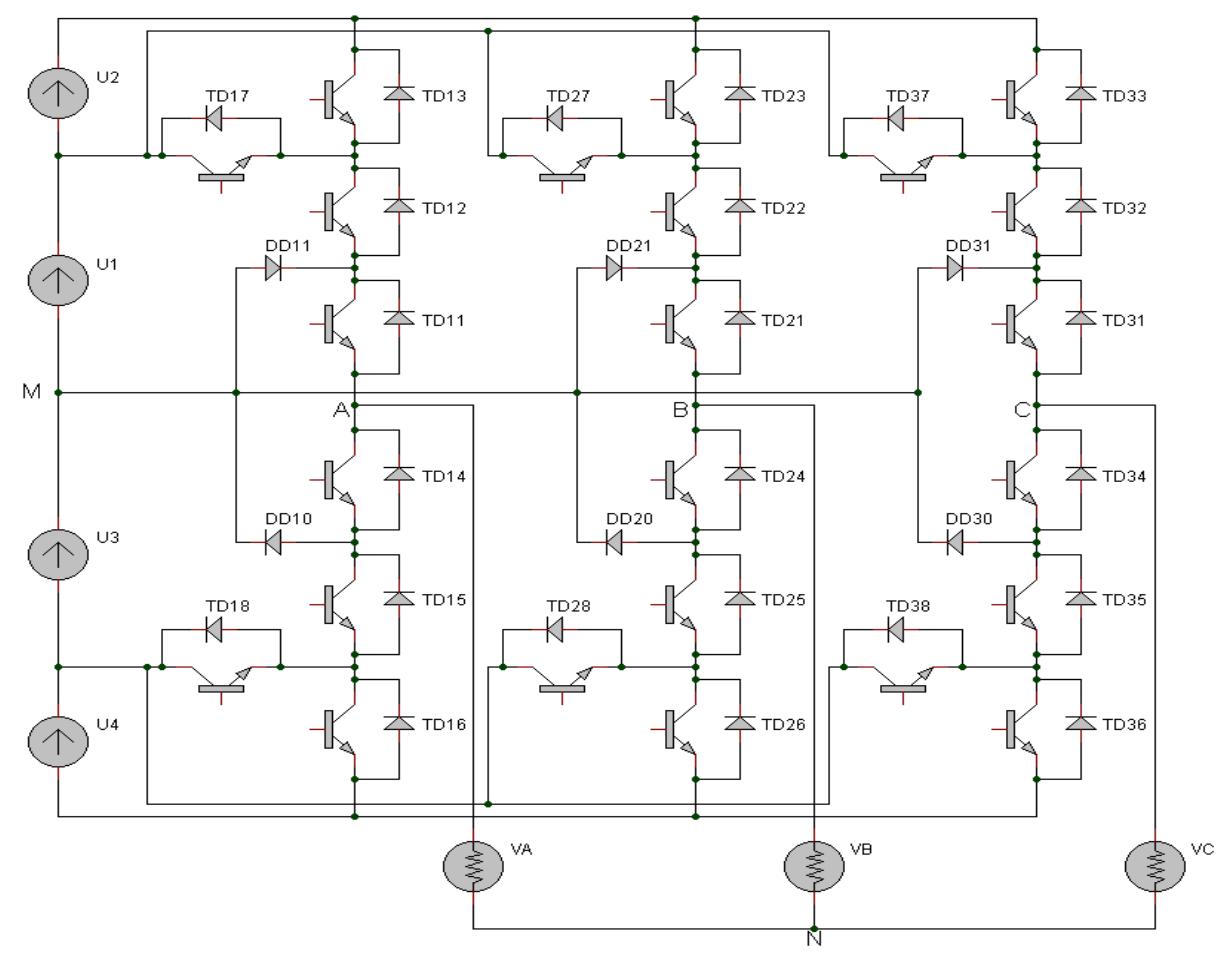

Fig. 1. The three-phase five-level NPC inverter

we find:

$\left\{\begin{array}{c}e_{3}=\frac{1}{\mathrm{~m}}\left[k_{1} e_{1}+\dot{\Omega}_{r e f}+c \Omega+\frac{T_{l}}{j}\right]-i_{s q} \\ e_{4}=\frac{1}{a M}\left[k_{2} e_{2}+\dot{\varphi}_{r e f}+a \varphi_{d}\right]-i_{s d}\end{array}\right.$

With this definition, taking into account the system (3) the dynamics $e_{1}$ and $e_{2}$ are written:

$\left\{\dot{e}_{1}=-k_{1} e_{1}+m \varphi_{d} e_{3}\right.$

$\left\{\dot{e}_{2}=k_{2} e_{2}+a M e_{4}\right.$

From (9), the errors dynamics are given by:

$$
\left\{\begin{array}{c}
\dot{e}_{1}=\left(i_{s q}\right)_{r e f}-A-m_{1} v_{s q} \\
=\frac{1}{a M}\left[k \dot{e}_{2}+\ddot{\varphi}_{r e f}+a \dot{\varphi}_{d}\right]-i_{s d} \\
\dot{e}_{4}=\left(\dot{i}_{s d}\right)_{r e f}-B-m_{1} v_{s d}
\end{array}\right.
$$

where

$\left\{\begin{array}{c}A=-\gamma i_{s q}-b P \Omega \varphi_{d}-P i_{s d}-a M \frac{i_{s q} i_{s d}}{\varphi_{d}} \\ B=\gamma i_{s q}-a b \Omega \varphi_{d}-P \Omega i_{s q}-a M \frac{i_{s q}{ }^{2}}{\varphi_{d}}\end{array}\right.$

Lyapunov function candidate is chosen following:

$v_{2}=\frac{1}{2}\left(e_{1}{ }^{2}+e_{2}{ }^{2}+e_{3}{ }^{2}+e_{4}{ }^{2}\right)$

Its derivative is:

$\dot{v}_{2}=e_{1} \dot{e}_{1}+e_{2} \dot{e}_{2}+e_{3} \dot{e}_{3}+e_{4} \dot{e}_{4}$

This equation can be rewritten in the following from
$\left\{\begin{array}{c}\dot{v}_{2}=K_{1} e_{1}{ }^{2}-K_{2} e_{2}{ }^{2}-K_{4} e_{4}{ }^{2}+e_{3}\left(K_{3} e_{3}+\left(\dot{i}_{s d}\right)_{r e f}\right) \\ -A-m_{1} v_{s d}+e_{4}\left(K_{4} e_{4}+\left(i_{s d}\right)_{r e f}-B-m_{1} v_{s d}\right)\end{array}\right.$

The choice $\mathrm{k} 3>0$ and $\mathrm{k} 4>0$ can be made such that $\dot{v}_{2}<$ 0 . We choose the $d$-axis and $q$-axis voltage control input as:

$\left\{\begin{array}{l}v_{s d}=\frac{1}{m_{1}}\left(K_{4} e_{4}\right)+\left(i_{s d}\right)_{r e f}-B \\ v_{s q}=\frac{1}{m_{1}}\left(K_{3} e_{3}\right)+\left(i_{s q}\right)_{r e f}-A\end{array}\right.$

So, (11) can be expressed as:

$\left\{\begin{array}{c}\dot{e}_{3}=-K_{3} e_{3}-m e_{1} \\ \dot{e}_{4}=-a M e_{2}-K_{2} e_{4}\end{array}\right.$

To show boundedness of all states, we can rearrange the dynamical equations from (10) and (17)

$\dot{e}=A e$

we can prove the boundedness of all the states, where $A$ can be shown to be Hurwitz.

\section{SimUlation RESUlts}

In this section we represent a simulation of the model of induction motor fed by a three-phase five-level voltage NPC inverter and controlled by the performing backstepping regulator, using MATLAB/SIMULINK. In order to evaluate the performance of the proposed controller, the testing was led at a high reference change. The dynamic response of IM is shown with Figures 2 to 6, and Table. 2 illustrates the considered simulation parameters for the control system.

Those results, shows; the stator voltage, the rotor speed and the rotor flux components in which present the 
performance of the backstepping control in the nominal case. It is observed that the rotor speed converges to the reference one without instabilities effects. As result the decoupling between the flux and the torque is better.

TABLE II. SimULATION PARAMETERS

\begin{tabular}{|l|l|l|}
\cline { 2 - 3 } \multicolumn{1}{c|}{} & Parameters & Numerical values \\
\hline Voltage DC bus & $V_{D C}$ & $500 \mathrm{~V}$ \\
\hline \multirow{5}{*}{ Induction Motor } & $R_{\mathrm{s}}$ & 4.85 \\
\cline { 2 - 3 } & $R_{r}$ & 3.805 \\
\cline { 2 - 3 } & $L_{\mathrm{s}}$ & 0.274 \\
\cline { 2 - 3 } & $L_{r}$ & 0.274 \\
\cline { 2 - 3 } & $M$ & 0.258 \\
\cline { 2 - 3 } & $P$ & 2 \\
\cline { 2 - 3 } & $J$ & 0.031 \\
\cline { 2 - 3 } & $f_{\mathrm{v}}$ & 0.001136 \\
\hline
\end{tabular}

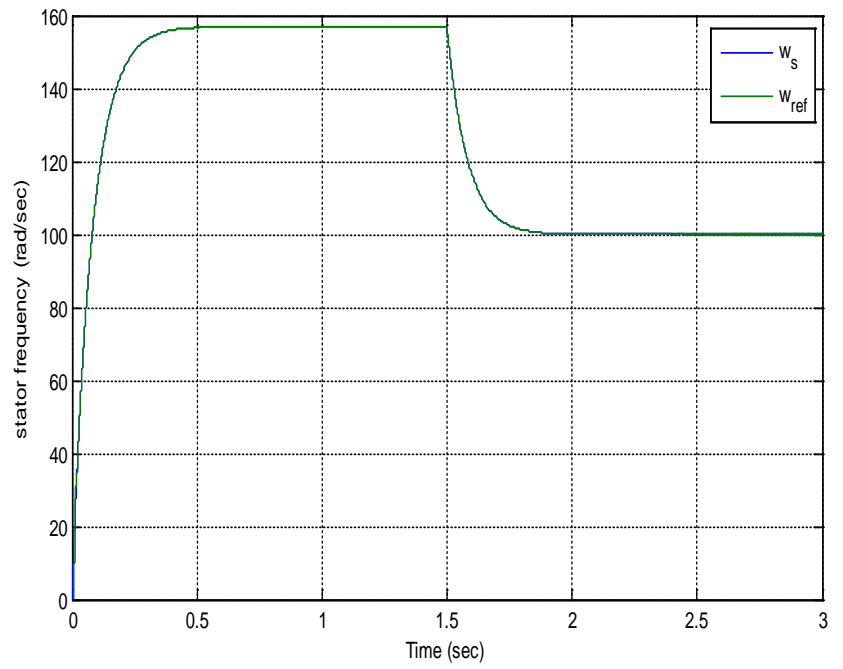

Fig. 2. Speed rotor

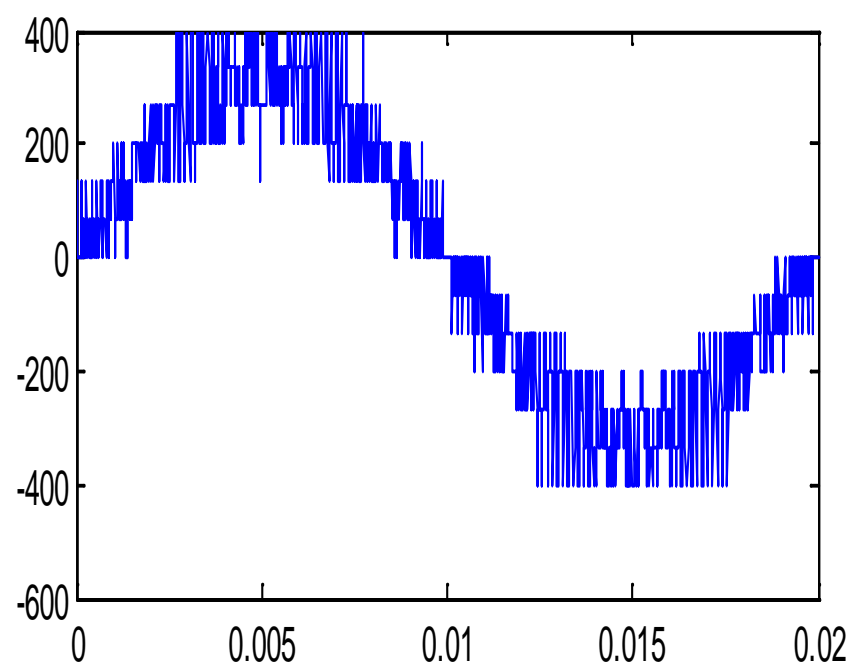

Fig. 3. Stator voltage inputs

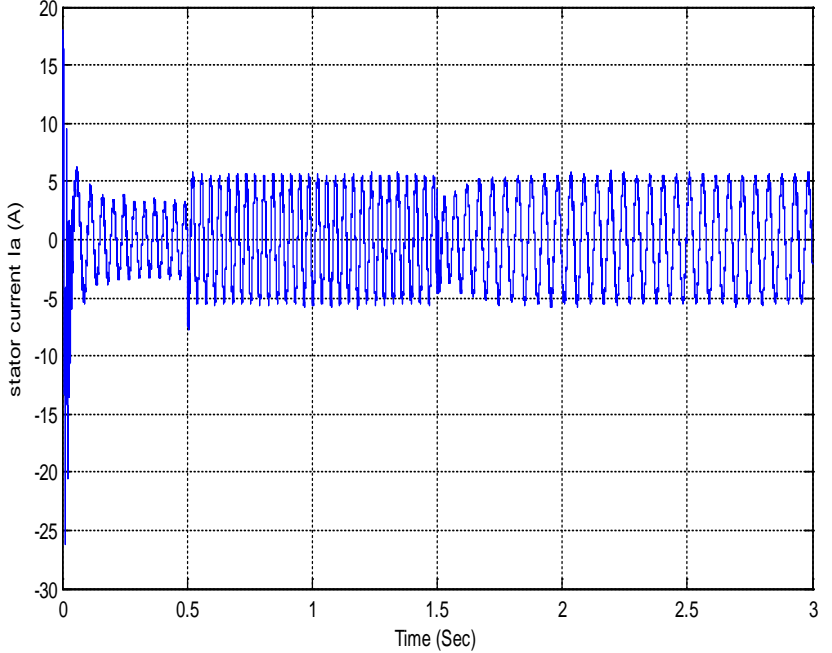

Fig. 4. Stator current

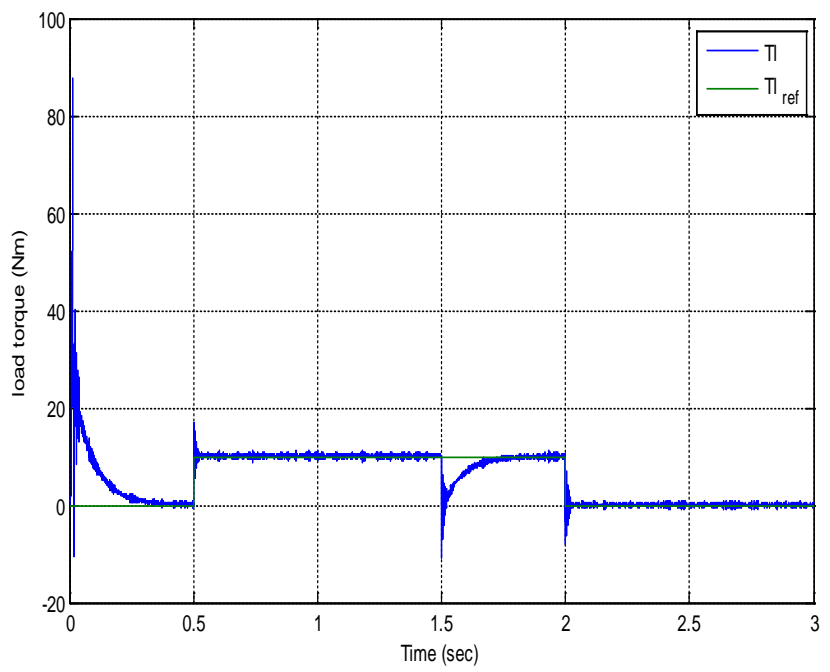

Fig. 5. Load torque

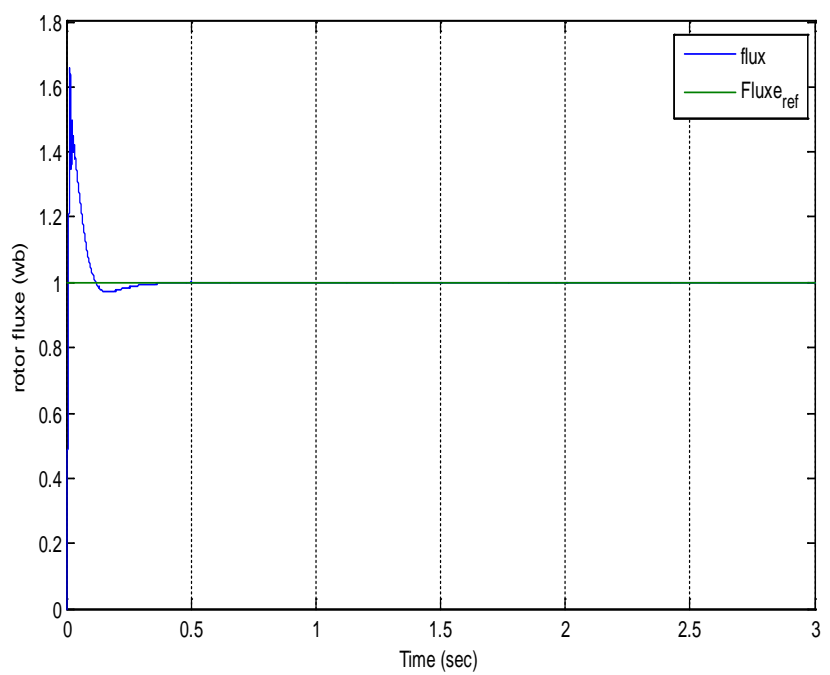

Fig. 6. Rotor flux 


\section{CONCLUSIONS}

In this paper, a nonlinear feedback controller based on a backstepping method for IM Fed by five-level NPC Inverter has been developed. To achieve global asymptotic stability of the proposed controller, Lyapunov theory is applied. Some simulation results were carried out to illustrate the effectiveness of the proposed control system. It is pointed out that the robustness of the controlled IM drive against speed and load torque variations is guaranteed. Furthermore, the proposed control scheme decreases considerably the torque ripples and assures good speed tracking without overshoot.

\section{REFERENCES}

[1] C. Heising, V. Staudt and A. Steimel, "Speed-sensorless stator-fluxoriented control of induction motor drives in traction”, 2010 First Symposium on Sensorless Control for Electrical Drives, Padova, pp. 100-106, 2010.

[2] S. Chaouch, M.S. Nait Said, “A high performance direct stator flux orientation control (DSFO) for speed sensorless induction motor drive” Second International Conference on Electrical Systems (ICES’06), Oum-Elbouaghi, pp 294-299, 8-10 May 2006.

[3] H. Chang, R. Wei, Q. Ge, X. Wang and H. Zhu, "Comparison of SVPWM for five level NPC H-bridge inverter and traditional five level NPC inverter based on line-voltage coordinate system", 18th International Conference on Electrical Machines and Systems (ICEMS), pp. 574-577, Pattaya, 2015.

[4] A. Rufer, N. Koch and N. Cherix, "Control of the Actively Balanced Capacitive Voltage Divider for a Five-Level NPC Inverter - Estimation of the Intermediary Levels Currents”, PCIM Europe 2016; International Exhibition and Conference for Power Electronics, Intelligent Motion, Renewable Energy and Energy Management, Nuremberg, pp. 1-7, Germany, 2016.

[5] H. Dallagi, "Modelling, simulation and analysis of three phase five level NPC inverter for induction motor drive”, 16th International Conference on Sciences and Techniques of Automatic Control and Computer Engineering (STA), pp. 562-569, Monastir, 2015.

[6] I. Benlaloui, S. Drid, L. Chrifi-Alaoui and D. Benoudjit, "Sensorless speed backstepping control of induction motor based on sliding mode observer: Experimental results”, 15th International Conference on Sciences and Techniques of Automatic Control and Computer Engineering (STA), pp. 923-928, Hammamet, 2014.

[7] J. Soltani and R. Yazdanpanah, "Robust Backstepping Control of Induction Motor Drives Using Artificial Neural Networks”, Power Electronics and Motion Control Conference (IPEMC'06), pp. 1-5, Shanghai, 2006.

[8] F. J. Lin, C. K. Chang and P. K. Huang, "FPGA-Based Adaptive Backstepping Sliding-Mode Control for Linear Induction Motor Drive”, IEEE Transactions on Power Electronics, vol. 22, no. 4, pp. 1222-1231, July 2007.

[9] K. Thakre and K. B. Mohanty, "Performance improvement of multilevel inverter through trapezoidal triangular carrier based PWM", International Conference on Energy, Power and Environment: Towards Sustainable Growth (ICEPE), pp. 1-6, Shillong, India, 2015.

[10] Calais, M., Borle, L. J., \& Agelidis, V. G. “Analysis of multicarrier PWM methods for a single-phase five level inverter", In Power Electronics Specialists Conference, 2001. PESC. 2001 IEEE 32nd Annual, vol. 3, pp. 1351-1356, 2001.

[11] RAHIM, Nasrudin A. and SELVARAJ, Jeyraj. "Multistring five-level inverter with novel PWM control scheme for PV application”, IEEE transactions on industrial electronics, vol. 57, no 6, p. 2111-2123, 2010.

[12] TEKWANI, P. N., KANCHAN, R. S., and GOPAKUMAR, K. “A dual five-level inverter-fed induction motor drive with common-mode voltage elimination and dc-link capacitor voltage balancing using only the switching-state redundancy-Part I”, IEEE Transactions on Industrial Electronics, vol. 54, no 5, pp. 2600-2608, 2007.

[13] J.L. Galvan, "Multilevel Converters: Topologies, Modelling, Space Vector Modulation Techniques and Optimizations", Ph.D. thesis, University of Seville, 2006.

[14] MCGRATH, Brendan Peter and HOLMES, Donald Grahame, "Multicarrier PWM strategies for multilevel inverters", IEEE transactions on industrial electronics, vol. 49, no 4, p. 858-867, 2002.

[15] BAI, Zhihong, ZHANG, Zhongchao, and ZHANG, Yao, “A generalized three-phase multilevel current source inverter with carrier phase-shifted SPWM", In IEEE Power Electronics Specialists Conference. IEEE, 2007. p. 2055-2060, 2007. 